\title{
Placement of a Stent within a Flow Diverter Improves Aneurysm Occlusion Rates
}

\author{
(D) Ocal, (D) A. Peker, (D) S. Balci, and (D) A. Arat
}

\begin{abstract}
BACKGROUND AND PURPOSE: Placement of a stent within a flow diverter has been described previously but its consequences have not been analyzed. We evaluated the clinical and angiographic results of stent placement within a flow diverter during the same treatment session.

MATERIALS AND METHODS: All patients treated with a Surpass flow diverter were retrospectively evaluated. Patients with previously deployed stents and procedures in which scaffolding stents, a second flow diverter, or intrasaccular devices were used were excluded. Patient and aneurysm characteristics and clinical and imaging follow-up results were compared between stented and nonstented Surpass flow-diverter groups and stent assisted coiling.

RESULTS: Thirty-five patients (41 aneurysms) were treated with a Surpass flow diverter only (monotherapy group), and in 33 patients (35 aneurysms), a stent was placed within the Surpass flow diverter (stented group). Stents were placed inside the Surpass flow diverter for a variety of reasons at the operator's discretion. No statistical difference was noted between the 2 groups in age, body weight, sex, history of thromboembolic events, smoking, platelet inhibition levels, hypertension, hyperlipidemia, diabetes mellitus, malignancy, and aneurysm location. Aneurysms in the stented group were larger than those in the monotherapy group (14.8 versus $9.1 \mathrm{~mm}, P<.001)$. The rate of clinically significant adverse events and complete aneurysm occlusion rates at 0-3 and 3-6 months (73.3\% versus $61.3 \%, P=.31$, and $84.8 \%$ versus $70.2 \%, P=.14)$ were similar. At $9-12$ months, a significantly higher proportion of aneurysms in the stented group achieved complete occlusion ( $93.9 \%$ versus $73.2 \%, P=.019)$. There was a trend toward a higher obliteration rate on final follow-up in the stented group (93.9\% versus $82.9 \%, P=.14)$.
\end{abstract}

CONCLUSIONS: Placement of a stent within a flow diverter increases the rate of aneurysm occlusion. We propose that these results are from improved flow-diverter apposition due to the higher radial force of intracranial stents.

ABBREVIATIONS: $\mathrm{FD}$ = flow diverter; $\mathrm{Mtg}=$ monotherapy group; SAC = stent-assisted coiling; Stg = stented group; RR = Raymond-Roy

$F^{\prime}$ low diverters (FDs) are effective in the treatment of intracranial aneurysms, and they cause gradual thrombosis of the aneurysm sac by redirecting flow and causing stagnation. Aneurysm occlusion rates after flow diversion at 6 months are around $75 \%$, and there is a rupture risk until complete occlusion occurs. ${ }^{1,2}$ Several adjunctive techniques have been described to increase the safety and efficacy of the flow diversion, including coiling or placement of other intrasaccular devices such as flow diverters or the Medina embolization device (Covidien/eV3/ Medtronic, Dublin, Ireland) or stent placement. ${ }^{3-5}$ Among these

Received June 17, 2019; accepted after revision August 13

From the Department of Radiology, Faculty of Medicine, Hacettepe University, Ankara, Turkey.

Please address correspondence to Anıl Arat, MD, Department of Radiology, School of Medicine, Hacettepe University, Sihhiye, 06100, Ankara, Turkey; e-mail:

anilarat@hotmail.com

http://dx.doi.org/10.3174/ajnr.A6237 techniques, stent placement has been proposed as a technique that enhances apposition and prevents device migration. ${ }^{5-8}$ However, this proposal remains speculative and has not been validated. Indeed, to date, there are only 17 patients in the literature in whom placement of a stent inside a flow diverter has been documented ${ }^{5-8}$ - that is, there is no comparative study assessing the safety of stent placement within a flow diverter and its effect on the outcome of aneurysms treated by flow diversion. We studied the safety and efficacy of stent placement within a single type of flow diverter during the same treatment session and discuss the rationale and results of this technique.

\section{MATERIALS AND METHODS Study Population}

All patients treated with a single type of flow diverter (Surpass; Stryker Neurovascular, Kalamazoo, Michigan) for an intracranial 

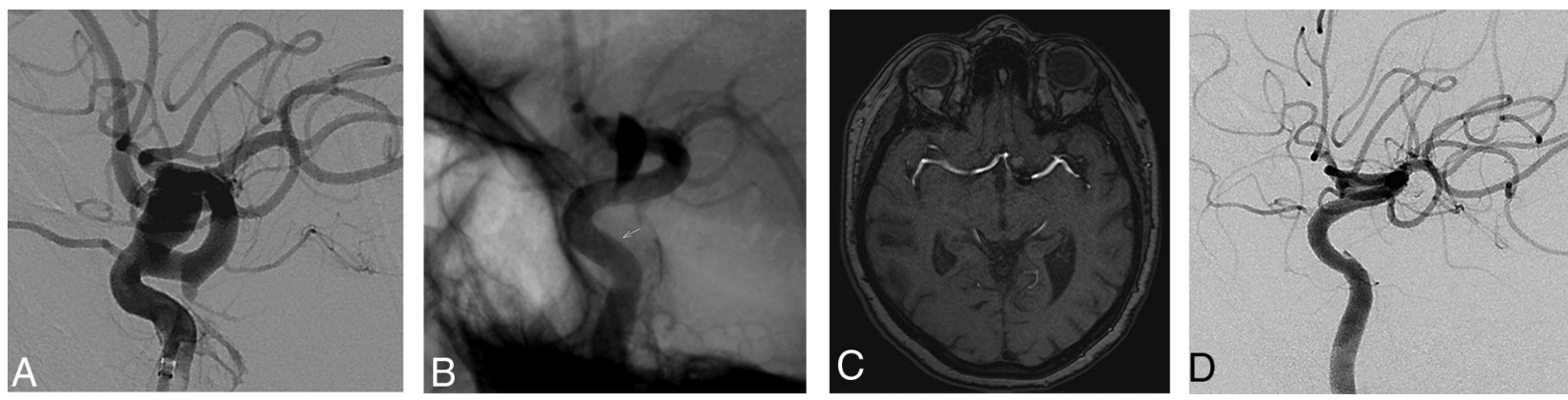

FIG 1. A, Left ICA angiogram shows a supraclinoid aneurysm. B, Angiogram after the deployment of the flow diverter shows good apposition of the device at the neck of the aneurysm but slight malapposition at the proximal landing zone (arrow). C, TOF-MRA image 3 months after the procedure shows residual filling in the aneurysm. $D$, Follow-up angiogram obtained 6 months after the procedure shows complete occlusion of the aneurysm. A filling defect is noted where the flow diverter was malapposed.

aneurysm in a single institution by a single operator between May 2013 and September 2017 were identified and evaluated retrospectively. Patients treated by placement of a flow diverter inside a scaffolding stent, adjunctive use of a second flow diverter (telescopic flow diverters), treatment with a flow diverter other than the Surpass device; those with ruptured aneurysms in the acute phase, patients previously treated by stent-assisted coiling, or those treated endosaccularly during the same session were excluded from the study, whereas tandem aneurysms were included and evaluated as separate aneurysms. Additionally, patients treated with a stent-assisted coiling technique in the same institution and by the same operator during the same period were identified. The included patients were evaluated for age, sex, weight, history of previous thromboembolic events, smoking, hypertension, diabetes, hyperlipidemia and malignancy, platelet inhibition levels on the day of treatment (percentage inhibition, VerifyNow P2Y12 assay; Accumetrics, San Diego, California), aneurysm location, maximum diameter and morphology (saccular versus fusiform/dissecting) of the aneurysm, follow-up imaging results (based on the Raymond-Roy [RR] scale), and clinically relevant adverse events (death or TIA/stroke or hemorrhage or any event resulting in change of the $\mathrm{mRS}$ ). A proximal circulation aneurysm was defined as any aneurysm located on the arteries below the superior cerebellar arteries in the posterior circulation and below the dural ring in the anterior circulation. The remaining aneurysms were classified as distal. An anterior circulation aneurysm was defined as an aneurysm originating from arteries of the carotid circulation, including aneurysms of the posterior communicating artery.

\section{General Description of the Procedure and Follow-Up}

The specifications and technical properties of the Surpass flow diverter have been previously described. ${ }^{9}$ Patients were pretreated with acetylsalicylic acid and clopidogrel (or prasugrel) on the basis of the previously described regimen in the literature. ${ }^{10}$ They were treated under general anesthesia and heparinization using biplane angiographic equipment (Artis zee; Siemens, Erlangen, Germany). Using a triaxial system, we deployed a single Surpass device across the aneurysm neck (or the aneurysmal segment in fusiform cases). An intracranial stent was placed within the freshly deployed Surpass device in the following situations: wide-neck or fusiform aneurysms where the operator wanted to exclude the risk of device prolapse/migration after removal of the deployment system (to pin the flow diverter), cases in which the landing zone was shorter than ideal (to prevent delayed migration due to foreshortening), the landing zone of the device being at an arterial bend (to enable better apposition), the flow diverter partially covering a major branch at the distal or proximal landing zone (to enable further shortening of the device and unjail the branch), and discrepancy of $\geq 2 \mathrm{~mm}$ between the diameters of the parent artery at the proximal and distal landing zones (Figs 1 and 2). After the procedure, the patients were advised to come back in 1-3 months for noninvasive angiographic imaging, in 3-6 months for DSA, later at 9-12 months, and annually after that for noninvasive angiographic imaging. Patients were kept on dual-antiplatelet therapy for 6 months, and clopidogrel (or prasugrel) was discontinued after the 6-month DSA.

\section{Statistical Analysis}

Continuous variables were reported as mean \pm SD. Categoric variables were compared by $\chi^{2}$ or Fisher exact tests, as appropriate. Student $t$ and Mann Whitney $\mathrm{U}$ tests were used for comparison of continuous variables as appropriate. Significance was set as $P<.05$.

Propensity score matching was performed to compare the monotherapy group (Mtg) and stented group (Stg) separately with those patients treated by stent-assisted coiling (SAC) during the same period. SPSS Statistics, Version 22.0 (IBM, Armonk, New York) was used for calculations. Matching was performed using a MatchIt package in R statistical and computing software, Version 3.5.0 (http://www.r-project.org/). Matching covariates were size and aneurysm location (anterior versus posterior and proximal versus distal). SAC and Mtg groups and SAC and Stg groups were matched in a 1:1 ratio, with the nearest calculated propensity logit, with a caliper width of $\leq 0.20$ of the SD of the propensity score logit. Subsequently, aneurysm occlusion rates were compared by a $\chi^{2}$ or Fisher exact test as appropriate.

We dichotomized the aneurysm size at $13 \mathrm{~mm}$ to see how aneurysm occlusion rates in larger-versus-smaller aneurysms were affected in a cohort in which stent placement within a FD was also used. We made a comparison for occlusion in the whole cohort at $0-3,3-6,9-12$ and, $>12$ months. Occlusion rates were compared by a $\chi^{2}$ or Fisher exact test as appropriate.

AJNR Am J Neuroradiol 40:1932-38 Nov 2019 www.ajnr.org 

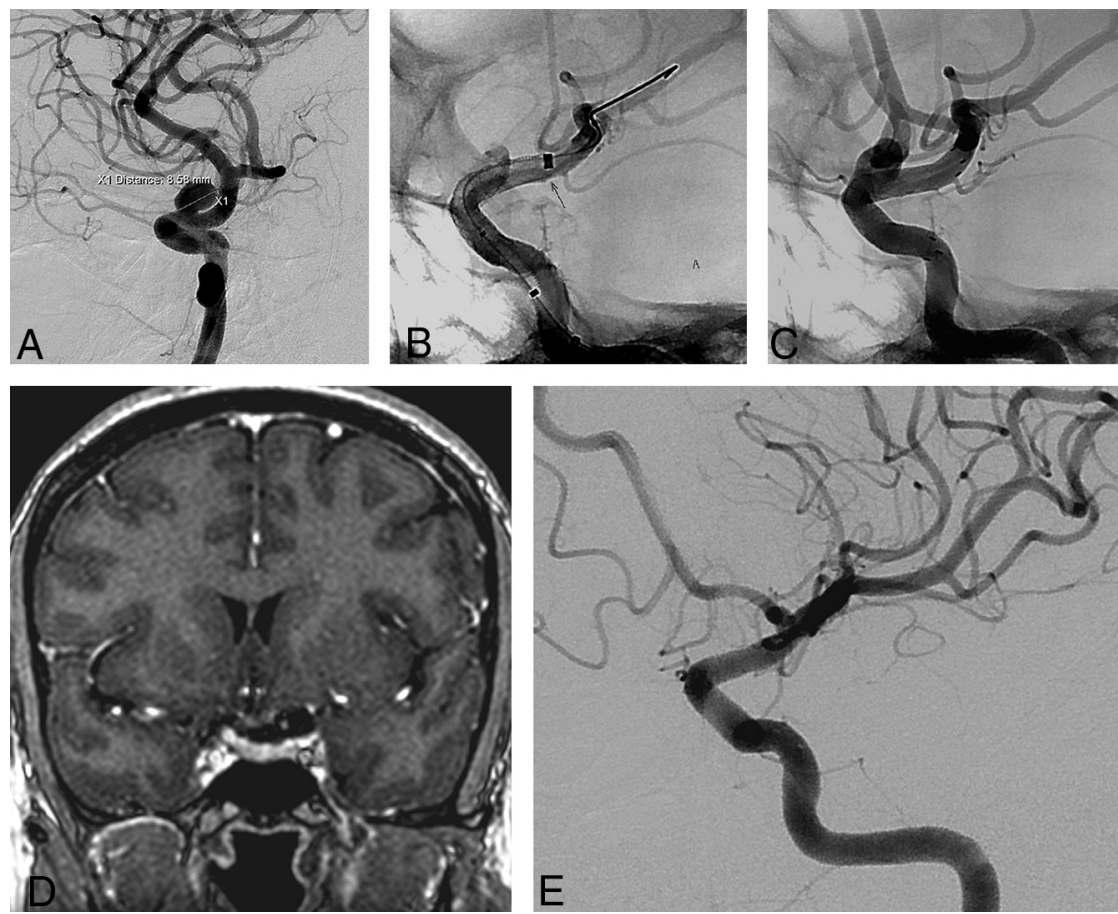

FIG 2. A, Left ICA angiogram shows a supraclinoid aneurysm similar to the aneurysm of the patient in Fig 1. B. Angiogram after deployment of the flow diverter shows malapposition at the distal end of the device (arrow). C, Angiogram at the end of the procedure shows good apposition of the device and a stent inside the device. $D$, Contrast-enhanced coronal MR image 3 months after the procedure shows no residual filling. E, Follow-up angiogram obtained 6 months after the procedure shows complete occlusion of the aneurysm.

Table 1: Comparison of categoric clinical variables in monotherapy and stented groups

\begin{tabular}{|c|c|c|c|c|c|}
\hline & \multicolumn{2}{|c|}{$\begin{array}{l}\text { Monotherapy } \\
\text { Group }(n=35)\end{array}$} & \multicolumn{2}{|c|}{$\begin{array}{c}\text { Stented Group } \\
(n=33)\end{array}$} & \multirow[b]{2}{*}{$P$} \\
\hline & No. & $\%$ & No. & $\%$ & \\
\hline \multicolumn{6}{|l|}{ Sex } \\
\hline Male & 14 & 40 & 11 & 33.3 & .561 \\
\hline Female & 21 & 60 & 22 & 66.7 & \\
\hline \multicolumn{6}{|c|}{ Prior thromboembolic event } \\
\hline Negative & 31 & 88.6 & 32 & 97 & .357 \\
\hline Positive & 4 & 11.4 & 1 & 3 & \\
\hline \multicolumn{6}{|l|}{ Smoking } \\
\hline Negative & 24 & 68.6 & 27 & 81.8 & .267 \\
\hline Positive & 11 & 31.4 & 6 & 18.2 & \\
\hline \multicolumn{6}{|c|}{ Hypertension } \\
\hline Negative & 24 & 68.6 & 23 & 69.6 & .920 \\
\hline Positive & 11 & 31.4 & 10 & 30.4 & \\
\hline \multicolumn{6}{|c|}{ Diabetes mellitus } \\
\hline Negative & 32 & 91.4 & 32 & 97 & .614 \\
\hline Positive & 3 & 8.6 & 1 & 3 & \\
\hline \multicolumn{6}{|c|}{ Hyperlipidemia } \\
\hline Negative & 33 & 94.2 & 30 & 90.9 & .668 \\
\hline Positive & 2 & 5.8 & 3 & 9.1 & \\
\hline \multicolumn{6}{|l|}{ Malignancy } \\
\hline Negative & 33 & 94.2 & 30 & 90.9 & .668 \\
\hline Positive & 2 & 5.8 & 3 & 9.1 & \\
\hline
\end{tabular}

and 43 were female; and the mean age was $49.9 \pm 14.8$ years (range, $12-$ 86 years).

The mean patient age did not differ between the monotherapy group (49.0 \pm 15 years) and the stented group (51.0 \pm 14.7 years, $P=.56$ ). Body weight; the proportion of female patients; prior history of thromboembolic events; and a history of smoking, hypertension, hyperlipidemia, diabetes mellitus, and malignancy were similar between the 2 groups. Results of point-of-care platelet inhibition tests were similar $(79.8 \%$ versus $78.7 \%$, $P=.92)$. The demographics of the 2 groups are summarized in Tables 1 and 2.

Aneurysms of the stented group were statistically significantly larger than in the monotherapy group (14.8 versus $9.1 \mathrm{~mm}, P<.001)$. There was no difference between the 2 groups with respect to aneurysm location (anterior-versus-posterior circulation, $P=.32$, and proximal versus distal to the circle of Willis, $P=.28$ ). The ratio of saccular and fusiform aneurysms in both groups was also similar (saccular/ fusiform, 32/9 versus 21/14, $P=.08$ ). There were 2 recurrent aneurysms in both groups, and all of them had been treated with coils in previous sessions. Two aneurysms had a previous history of rupture in the stented group. There was no difference in the rate of bifurcation aneurysms in each group (2 patients in the Mtg versus 1 patient in the Stg, $P=.65$ ).

The types of adjunctive stents were Atlas (Stryker) in 22 cases; coronary stents in 8 cases; and Neuroform (Stryker), Enterprise (Codman \& Shurtleff, Raynham, Massachusetts), and LEO (Balt Extrusion, Montmorency, France) stents in 1 case each. Although there was a trend toward earlier complete occlusion (100\%) of aneurysms in the stented group, the difference in complete aneurysm occlusion rates was not statistically significant at $0-3$ and 36 months of follow-up $(73.3 \%$ versus $61.3 \%, P=.31$, and $84.8 \%$ versus $70.2 \%$,

\section{RESULTS}

A total of 68 patients with 76 aneurysms were identified. Thirtyfive patients with 41 aneurysms were in the Mtg, and 33 patients with 35 aneurysms, in the Stg. Twenty-five patients were male
$P=.14)$. Nine- to 12 -month follow-up showed a significantly higher proportion of aneurysms that achieved complete occlusion in the stented group compared with the monotherapy group (93.9\% versus $73.1 \%, P=.019)$. There was no significant difference in complete 
Table 2: Comparison of continuous clinical variables in monotherapy and stented groups

\begin{tabular}{|c|c|c|c|c|c|}
\hline \multirow[b]{2}{*}{ Variable } & \multicolumn{2}{|c|}{ Monotherapy Group } & \multicolumn{2}{|c|}{ Stented Group } & \multirow[b]{2}{*}{$P$} \\
\hline & Mean & $\begin{array}{l}\text { Median } \\
\text { (Range) }\end{array}$ & Mean & $\begin{array}{l}\text { Median } \\
\text { (Range) }\end{array}$ & \\
\hline Age & $49.0 \pm 15.0$ & $50(12-86)$ & $51.0 \pm 14.7$ & $52(22-84)$ & .561 \\
\hline Weight & $73.7 \pm 15.2$ & 78 (41-101) & $68.7 \pm 11.5$ & $66(47-96)$ & .115 \\
\hline $\begin{array}{l}\text { Platelet inhibition level } \\
(\%)^{\mathrm{a}}\end{array}$ & $79.8 \pm 16.2$ & $78(44-100)$ & $78.7 \pm 20.4$ & $81(33-100)$ & .925 \\
\hline $\begin{array}{l}\text { Aneurysm diameter } \\
(\mathrm{mm})\end{array}$ & $9.1 \pm 10.8$ & $5.0(2-56)$ & $14.8 \pm 9.0$ & $13(3-40)$ & $<.001^{\mathrm{b}}$ \\
\hline
\end{tabular}

${ }^{a}$ Verify Now P2Y12 assay.

${ }^{\mathrm{b}}$ Statistical significance.

Table 3: Comparison of angiographic variables in monotherapy and stented groups

\begin{tabular}{|c|c|c|c|c|c|}
\hline & \multicolumn{2}{|c|}{$\begin{array}{l}\text { Monotherapy } \\
\text { Group }\end{array}$} & \multicolumn{2}{|c|}{ Stented Group } & \multirow[b]{2}{*}{$P$} \\
\hline & No. & $\%$ & No. & $\%$ & \\
\hline \multicolumn{6}{|l|}{ Aneurysm location $^{\mathrm{a}}$} \\
\hline Proximal & 36 & 87.8 & 34 & 97.1 & .281 \\
\hline Distal & 5 & 12.2 & 1 & 2.9 & \\
\hline \multicolumn{6}{|l|}{ Aneurysm location ${ }^{a}$} \\
\hline Anterior & 34 & 82.9 & 32 & 91.4 & .326 \\
\hline Posterior & 7 & 17.1 & 3 & 8.6 & \\
\hline \multicolumn{6}{|c|}{ Aneurysm morphology } \\
\hline Saccular & 32 & 78.0 & 21 & 60.0 & .087 \\
\hline Fusiform & 9 & 22.0 & 14 & 40.0 & \\
\hline \multicolumn{6}{|c|}{ 0- to 3-mo follow-up } \\
\hline Total occlusion & 19 & 61.3 & 22 & 73.3 & .316 \\
\hline Residual filling & 12 & 38.7 & 8 & 26.7 & \\
\hline \multicolumn{6}{|c|}{ 3- to 6-mo follow-up } \\
\hline Total occlusion & 26 & 70.2 & 28 & 84.8 & .147 \\
\hline Residual filling & 11 & 29.8 & 5 & 15.2 & \\
\hline \multicolumn{6}{|c|}{ 9- to 12-mo follow-up } \\
\hline Total occlusion & 30 & 73.2 & 31 & 93.9 & $.019^{\mathrm{b}}$ \\
\hline Residual filling & 11 & 26.8 & 2 & 6.1 & \\
\hline \multicolumn{6}{|l|}{$>12$-mo follow-up } \\
\hline Total occlusion & 34 & 82.9 & 31 & 93.9 & .149 \\
\hline Residual filling & 7 & 17.1 & 2 & 6.1 & \\
\hline
\end{tabular}

a Please see the Materials and Methods section for the description of each of these variables.

${ }^{\mathrm{b}}$ Statistical significance.

aneurysm obliteration rates on the final follow-up after 1 year $(93.9 \%$ versus $82.9 \%, P=.14$ ). Aneurysm characteristics and follow-up results are summarized in Table 3.

There was no clinically relevant adverse event in either group and no mortality. One parent artery occlusion occurred in each group during the follow-up period. In the monotherapy group, there were 2 patients with severe in-stent stenosis. One of these patients developed transient ischemic attacks and was managed with adjustment of the dual-antiplatelet treatment. The second patient was treated with balloon angioplasty and stent placement without an adverse event, and the residual aneurysm was treated with placement of another flow diverter during the same procedure. This was the only patient who needed retreatment in the whole cohort.

When the SAC group and either the Mtg and Stg were compared, there were significant differences in terms of location, size, and morphology of the aneurysms because we frequently reserve SAC for distal bifurcation aneurysms and FDs for sidewall or fusiform aneurysms. Thus, we decided to perform propensity score analysis to adjust for the selection bias between groups inherent in an analysis of aneurysm occlusion. After we performed a 1:1 match, 30 patients were selected in each of the monotherapy and SAC groups and 21 patients remained in each of the Stg and SAC groups. Statistical analysis after propensity score matching revealed that the total occlusion rate based on the last DSA follow-up available in each group was similar in SAC versus Mtg (mean DSA follow-up duration, 8.1 versus 6.8 months; occlusion rate, $65.3 \%$ versus $73.3 \%$ ) and SAC versus Stg (mean DSA follow-up duration, 9.9 versus 7.4 months; occlusion rate, $70.5 \%$ versus $94.7 \%$ ). When an "acceptable occlusion" criterion (based on the Raymond-Roy classification) of RR1 + RR2 instead of only RR1 was considered, the acceptable occlusion rates were 88.4 versus 93.3 in the SACversus-Mtg group and 88.2 versus 94.7 in the Stg group. The differences were not significant among any of the comparison groups.

There was no significant difference in the aneurysm occlusion rate (RR1) during any of the follow-up periods $(P=.49, \quad P=.66, \quad P=.22, \quad P=.68$, respectively) in aneurysms of $\geq 13 \mathrm{~mm}$ versus those that were smaller. We noted that of the 26 aneurysms that were $\geq 13 \mathrm{~mm}, 18$ actually belonged to the Stg. The evaluation of the available follow-up imaging in these 18 patients yielded a total occlusion rate of $62.5 \%$, increasing to $82.4 \%$ and then to $94.1 \%$ and then becoming stable for the follow-up periods.

Of the 9 patients who had a cerebral DSA beyond 12 months (range, 13-46 months; mean, 28.5 months; median, 24 months), only 1 patient who was treated with FD placement-only had residual filling of her aneurysm.

\section{DISCUSSION}

The combined use of a stent and flow diverter has been thought to decrease the success rate of flow diverters. ${ }^{11}$ However, this possibility refers to previously placed stents, and the consequences of placing a stent within a flow diverter have not been studied. Although there are 4 reports in the literature mentioning a total of 17 stents placed within flow diverters for better wall apposition, the safety or efficacy of this technique is unknown. ${ }^{5-8}$

We wanted to evaluate the safety and utility of stent placement within a freshly deployed flow diverter by comparing the aneurysms treated by flow diverters only (Mtg) with those treated by flow diverters followed by stents during the same procedure 
(Stg). We included only aneurysms treated by a single type of flow diverter without adjunctive intrasaccular treatment so that the study population would be uniform as to the efficacy of the device used (Surpass device) - that is, we wanted to eliminate the variables of device type and adjunctive treatments. Both groups of patients were also similar for all variables (age, sex, history of a prior thromboembolic event, smoking, hypertension, diabetes mellitus, hyperlipidemia, malignancy, and platelet inhibition level) except for the size of the aneurysm. The mean size of aneurysms was $14.8 \mathrm{~mm}$ in the Stg and significantly higher than the Mtg $(9.1 \mathrm{~mm})$. Because a cutoff point of $13 \mathrm{~mm}$ was suggested for lower occlusion and higher complication rates ${ }^{12}$ in flow diversion, we would actually expect a lower occlusion and a higher complication rate for the Stg. This was not the case for our cohort. Despite a larger aneurysm size in the Stg, the occlusion rates were higher. Additionally, there was no difference in the occurrence of significant adverse events between the 2 groups.

An earlier occlusion was noted in the Stg with statistical significance at 9-12 months. As the aneurysms in the Mtg progressed to occlusion after 1 year, the difference between occlusion rates of the groups decreased, yet there was still a trend in the Stg toward better occlusion rates at or after 1 year.

These findings suggest that stent placement within flow diverters does not significantly increase the risk of flow diversion and is associated with increased efficacy. Indeed, adverse events without clinical symptoms, namely fish mouthing and/or in-stent stenosis, were only observed in the Mtg, hinting at enhancement of safety with stent placement, which is an outcome that remains to be definitely demonstrated.

Braided stents and especially flow diverters have a lower radial force compared with laser-cut stents. ${ }^{5-7}$ Consequently, flow diverters may not appose the arterial wall, especially in arterial segments with tight bends. ${ }^{11}$ Hence, stents have been used only rarely for the apposition or anchoring of flow diverters in several patients as noted above. ${ }^{5-7}$ The latest clinical and preclinical data suggest that incomplete wall apposition causes inhomogeneous and delayed endothelial coverage of stent struts and aneurysm neck, ${ }^{13,14}$ and suboptimal apposition at the aneurysm neck causes persistent filling of the aneurysm. ${ }^{15}$ Treatment failure rates (Raymond-Roy grade III) in malapposed flow diverters were $41.2 \%$ and significantly higher than in fully apposed devices $(9.6 \%)$ in a study with 213 patients. ${ }^{16}$ In our study, there were several reasons for stent placement within the flow diverter and not all stents were deployed for better apposition. Nevertheless, the better angiographic outcome in the Stg was presumably due to better wall apposition regardless of the presence of an angiographically visible overt malapposition. Incomplete apposition is not only a handicap in the periprocedural period, it also leads to delayed stent occlusions in the coronary arteries ${ }^{17}$ and after flow diversion, ${ }^{18}$ which may occur as late as 3 years after device placement. ${ }^{19-21}$ Improvement of apposition by stents may help maintain flow-diverter patency in the long term.

Several strategies exist to enhance flow-diverter apposition to the arterial wall. Among these, the most commonly used ones are loading the device during delivery and recrossing it with the delivery microcatheter after deployment. Angioplasty is another technique that is adopted by some authors. However, angioplasty may paradoxically worsen device apposition, and this may be detected only by advanced imaging methods such as optical coherence tomography. ${ }^{15}$ Balloon angioplasty can also result in thrombus formation inside the flow diverter ${ }^{15}$ or, in case of a short landing zone, foreshortening and device prolapse into the aneurysm. $^{22}$

It may be argued that placement of a stent inside the flow diverter will increase the metal coverage and consequently result in both an enhanced flow diversion and also an increased rate of perforator injury in vulnerable segments like the M1 segment of the MCA or the posterior circulation. Wall coverage of the current intracranial stents is very low, in the range of $10 \%-15 \%$ at most, and the cumulative coverage of overlapping devices is much less than the numeric sum of the coverage of telescoped devices. ${ }^{23}$ The minimal increase of coverage by the intracranial stent is likely neither to cause an increase in the rate of perforator injury nor to result in an appreciable increase in flow diversion.

After propensity score matching, there was no statistically significant difference in the occlusion rates of cerebral aneurysms between SAC and either of the FD groups ( $\mathrm{Mtg}$ and Stg). However, there was a clear trend in both the Stg and Mtg for an increased rate of total occlusion compared with the patients with stent-assisted coiling. This finding is concordant with those previously reported in the literature using similar methodology for comparison of SAC and flow diversion. ${ }^{24,25}$ We believe that the absence of a statistically significant difference results largely from the low number of patients remaining in the study when propensity score matching was performed. Thus, our findings can only suggest that increased aneurysmal occlusion is the result of the use of a flow diverter rather than placement of a regular stent for SAC when flow diversion is compared with SAC. Although per our results, a statistical difference in favor of Stg compared with Mtg exists during early follow-up, larger cohorts are needed to validate this finding. It is conceivable that such larger cohorts may reveal differences in mid- or late-term follow-up periods as well.

One other unexpected result was the diminution of the gap between the occlusion rates of large-versus-small aneurysms as previously reported in the literature. ${ }^{12,26}$ In our whole cohort of patients treated with flow diversion in this study, there was no difference in the occlusion rates of aneurysms of $\geq 13 \mathrm{~mm}$ in diameter versus those aneurysms $<13 \mathrm{~mm}$ in diameter. Because 18 of the 26 aneurysms were treated with additional stent placement in the $\geq 13 \mathrm{~mm}$ subgroup (reaching $94 \%$ occlusion at 1 year in those that were stented), it is possible that the absence of a significant difference arises from the higher obliteration rates in the Stg. Nevertheless, the absence of such significance should be appraised with caution in studies like ours that have a limited number of patients.

There are 2 major disadvantages of stent placement within the flow diverter. The first one is the risk of flow-diverter migration during recrossing of the device or during the microcatheter exchange maneuver through the flow diverter. The second is cost. Fortunately, there is a matching intracranial stent for each flow diverter in terms of a compatible delivery microcatheter for all of the current flow diverters except for the Surpass flow diverter, 
for which a technique to place a stent without an intracranial exchange maneuver has been described. ${ }^{27}$ The stent is certainly an additional cost of the procedure. However, placement of a stent results in a comparable increase in cost with regard to the other adjunctive methods used to increase the efficiency of flow diverters such as intrasaccular flow diverters, ${ }^{4}$ Medina $^{28}$ embolization device, regular coils, ${ }^{29}$ or telescopic placement of another flow diverter. Because of the concern related to cost, we suggest that stent placement within a flow diverter should be selective and limited to bailout situations such as those listed in the previous section of our article and to those aneurysms that are expected to have a lower rate of occlusion by placement of a single flow diverter (eg, large and giant aneurysms).

The main limitations of this study include its retrospective nature and relatively small sample size. None of the stents we deployed inside flow diverter have been approved for such use, and this technique is an off-label use of these stents. Finally, only 1 type of flow diverter was examined in this study, and other types of flow diverters need to be studied to verify the proposed relation of device apposition and aneurysm occlusion.

\section{CONCLUSIONS}

Our study demonstrated, for the first time, the possible consequences of stent placement within a flow diverter. Our findings were based on the comparison of aneurysms treated by a bare flow diverter and those in which a laser-cut stent was placed within a flow diverter for a variety of different reasons. The trend toward earlier occlusion in the stented arm is promising and calls for scrutiny of the previously reported animal studies that put forward subtle flow-diverter malapposition as a cause of flow-diverter failure. Our findings need to be verified in larger cohorts, preferably from multicenter registries, and cannot be generalized to routine clinical scenarios or all neurointerventional practices. However, operators may individually consider stent placement within a freshly deployed flow diverter in selected situations as in our cases, bearing in mind that aside from bailing out a troubled flow-diversion procedure, stent placement may potentially help with occlusion rates without significantly increasing the risk of the procedure.

\section{REFERENCES}

1. Akgul E, Onan HB, Akpinar S, et al. The DERIVO embolization device in the treatment of intracranial aneurysms: short- and midterm results. World Neurosurg 2016;95:229-40 CrossRef Medline

2. Becske T, Kallmes DF, Saatci I, et al. Pipeline for uncoilable or failed aneurysms: results from a multicenter clinical trial. Radiology 2013;267:858-68 CrossRef Medline

3. Bhogal P, AlMatter M, Hellstern V, et al. The combined use of intraluminal and intrasaccular flow diversion for the treatment of intracranial aneurysms: report of $\mathbf{2 5}$ cases. Neurointervention 2018; 13:20-31 CrossRef Medline

4. Lescher S, Du Mesnil de Rochemont R, Berkefeld J. Woven Endobridge (WEB) device for endovascular treatment of complex unruptured aneurysms-a single center experience. Neuroradiology 2016;58:383-90 CrossRef Medline

5. Amuluru K, Al-Mufti F, Roth W, et al. Anchoring Pipeline flow diverter construct in the treatment of traumatic distal cervical carotid artery injury. Intervent Neurol 2017;6:153-62 CrossRef Medline

6. Kuhn AL, Wakhloo AK, Gounis MJ, et al. Use of self-expanding stents for better intracranial flow diverter wall apposition. Interv Neuroradiol 2017;23:129-36 CrossRef Medline

7. Rahal JP, Dandamudi VS, Heller RS, et al. Use of concentric Solitaire stent to anchor Pipeline flow diverter constructs in treatment of shallow cervical carotid dissecting pseudoaneurysms. $J$ Clin Neurosci 2014;21:1024-28 CrossRef Medline

8. Kühn AL, Rodrigues KM, Wakhloo AK, et al. Endovascular techniques for achievement of better flow diverter wall apposition. Interv Neuroradiol 2018;25:344-47 CrossRef Medline

9. Topcuoglu OM, Arat A, Peker A, et al. Intermediate catheter placement distal to the cerebral aneurysm during flow diversion embolization with the Surpass device. J Neurointerv Surg 2018;10:e35 CrossRef Medline

10. De Vries J, Boogaarts J, Van Norden A, et al. New generation of flow diverter (Surpass) for unruptured intracranial aneurysms: a prospective single-center study in 37 patients. Stroke 2013;44:1567-77 CrossRef Medline

11. Shapiro M, Becske T, Nelson PK. Learning from failure: persistence of aneurysms following Pipeline embolization. J Neurosurg 2017; 126:578-85 CrossRef Medline

12. Kaya T, Daglioglu E, Gurkas E, et al. Silk device for the treatment of intracranial aneurysms, Part 2: factors related to clinical and angiographic outcome. Turk Neurosurg 2016;26:533-37 CrossRef Medline

13. Foin N, Gutierrez-Chico JL, Nakatani S, et al. Incomplete stent apposition causes high shear flow disturbances and delay in neointimal coverage as a function of strut to wall detachment distance: implications for the management of incomplete stent apposition. Circ Cardiovasc Interv 2014;7:180-89 CrossRef Medline

14. Marosfoi M, Langan ET, Strittmatter L, et al. In situ tissue engineering: endothelial growth patterns as a function of flow diverter design. J Neurointerv Surg 2017;9:994-98 CrossRef Medline

15. King RM, Brooks OW, Langan ET, et al. Communicating malapposition of flow diverters assessed with optical coherence tomography correlates with delayed aneurysm occlusion. J Neurointerv Surg 2018;10:693-97 CrossRef Medline

16. US Food and Drug Administration. Summary of Safety and Effectiveness Data: Surpass Embolization Device 2018; P170024. https://www.accessdata.fda.gov/cdrh_docs/pdf17/P170024B.pdf. Accessed May 12, 2019

17. Souteyrand G, Amabile N, Mangin L, et al. Mechanisms of stent thrombosis analysed by optical coherence tomography: insights from the national PESTO French registry. Eur Heart J 2016; 37:1208-16 CrossRef Medline

18. Berge J, Biondi A, Machi P, et al. Flow-diverter Silk stent for the treatment of intracranial aneurysms: 1-year follow-up in a multicenter study. AJNR Am J Neuroradiol 2012;33:1150-55 CrossRef Medline

19. Klisch J, Turk A, Turner R, et al. Very late thrombosis of flowdiverting constructs after the treatment of large fusiform posterior circulation aneurysms. AJNR Am J Neuroradiol 2011;32:62732 CrossRef Medline

20. Oishi $\mathrm{H}$, Teranishi K, Nonaka S, et al. Symptomatic very delayed parent artery occlusion after flow diversion stent embolization. Neurol Med Chir (Tokyo) 2016;56:350-53 CrossRef Medline

21. Potts MB, Shapiro M, Zumofen DW, et al. Parent vessel occlusion after Pipeline embolization of cerebral aneurysms of the anterior circulation. J Neurosurg 2017;127:1333-41 CrossRef Medline

22. Srinivasan VM, Carlson AP, Mokin M, et al. Prolapse of the Pipeline embolization device in aneurysms: incidence, management, and outcomes. Neurosurg Focus 2017;42:E16 CrossRef Medline

23. Shapiro M, Raz E, Becske T, et al. Building multidevice Pipeline constructs of favorable metal coverage: a practical guide. AJNR Am J Neuroradiol 2014;35:1556-61 CrossRef Medline

24. Chalouhi N, Tjoumakaris S, Starke RM, et al. Comparison of flow diversion and coiling in large unruptured intracranial saccular aneurysms. Stroke 2013;44:2150-54 CrossRef Medline 
25. Zhang Y, Zhou Y, Yang P, et al. Comparison of the flow diverter and stent-assisted coiling in large and giant aneurysms: safety and efficacy based on a propensity score-matched analysis. Eur Radiol 2016;26:2369-77 CrossRef Medline

26. Briganti F, Leone G, Cirillo L, et al. Postprocedural, midterm, and long-term results of cerebral aneurysms treated with flow-diverter devices: 7-year experience at a single center. Neurosurg Focus 2017;42:E3 CrossRef Medline

27. Ocal O, Arat A, Peker A, et al. Better wall apposition of Surpass device with Atlas stent: a new and easy technique. In: Proceedings of the 14th Congress of the World Federation of Interventional and Therapeutic Neuroradiology. Budapest, Hungary. October 16-19, 2017

28. Aguilar Perez M, Bhogal P, Martinez Moreno R, et al. The Medina Embolic Device: early clinical experience from a single center. Neurointerv Surg 2017;9:77-87 CrossRef Medline

29. Nossek E, Chalif DJ, Chakraborty S, et al. Concurrent use of the Pipeline Embolization Device and coils for intracranial aneurysms: technique, safety, and efficacy. J Neurosurg 2015;122:904-11 CrossRef Medline 